\title{
Treatment and outcome of herniated lumbar intervertebral disk in a referral hospital in Kenya
}

\author{
K. W. Ongeti, BSc., MBChB, J. A. Ogeng'o, PhD, P. K. Bundi, BSc., P. O. Box 45 Kikuyu, Kenya and L.N. Gakuu, MMed, \\ FCS, (ECSA), Associate Professor, Department of Orthopaedics Surgery, College of Health Sciences, University of \\ Nairobi, P.O. Box 19676 - 00200, Nairobi, Kenya
}

Correspondence to: Dr. K. W. Ongeti, PCEA Kikuyu Hospital, P. O. Box 45 Kikuyu, Kenya. Email: kongeti@yahoo.com

\begin{abstract}
Background: Prolapsed lumbar intervertebral disk (PID) disease can be managed conservatively or surgically with different outcomes.

Objective: The present study aimed at assessing the management and outcomes of slipped intervertebral disk disease at the Kenyatta National hospital.
\end{abstract}

Design: A retrospective cross-sectional study.

Setting: Kenyatta National Hospital (KNH) a referral and teaching hospital in Kenya.

Patients and Methods: Consecutive files of all cases of slipped intervertebral disk disease from January 1997 to December 2007 were retrieved from the Medical records at the Kenyatta National Hospital. The biodata, management methods and the outcomes of the procedures were recorded. The collected data were analyzed using the SPSS $\mathbf{1 7 . 0}$ for Windows.

Results: Six hundred and three cases were reviewed. All patients received analgesics and bed rest. Five percent of the patients were put on bilateral traction for two weeks while $4 \%$ of the patients had corsets. Thirty five per cent of the patients were surgically managed. Over a third of the surgically managed patients had laminectomies. Microdiscectomy was increasingly popular in the latter half of the study period. Of the managed patients $95 \%$ reported improvement while $92 \%$ were complication free. The rate of reherniation and reoperation was $1.5 \%$ and $1.2 \%$ respectively.

Conclusion: The management of PID at Kenyatta National Hospital is largely successful with few cases of complications. In selected patients both conservative and surgical care are used in tandem. Microdiscectomy is an increasingly popular surgical procedure at the $\mathrm{KNH}$.

\section{INTRODUCTION}

Both conservative and surgical methods have been used to manage slipped lumbar intervertebral disc disease (1). The goal of treatment in cases of lumbar disk herniation is to return the patient to normal activities as quickly as possible. Therefore unnecessary surgery should be avoided (2). However about $10 \%$ of patients with lumbar disk herniation will ultimately require surgery (3).Surgery is recommended if the sciatica is severe and disabling and tension signs are positive, if symptoms persist without improvement for longer or if findings on clinical examination and in diagnostic tests are consistent with nerve root compromise.Surgical decompression options include discectomy, fenestration, and laminectomy(3).We report an eleven year review, the mode of management of all PID patients at Kenyatta National Hospital with their documented outcomes.

\section{MATERIALS AND METHODS}

An ethical approval was sought from the ethical review committee $\mathrm{KNH}$ and University of Nairobi. All patients' files with a diagnosis of prolapsed intervertebral disk disease from January 1997 to December 2008 were retrieved from the hospital's records department. Biodata, management of the patient and the outcome of the procedure were noted and recorded in the data sheet. The data collected were analyzed using SPSS ${ }^{\circledR}$ version 17.0 for Windows ${ }^{\circledR}$. The surgical procedure of choice and the surgical outcome was determined and compared for the gender groups. The students t-test 
was used to determine the significance of the means while the Pearson's test was used for correlation. Tables and Figures were used to illustrate the findings. A pvalue of $\leq 0.05$ was considered significant.

\section{RESULTS}

Six hundred and three patients were evaluated. There were 267 (44.3\%) males and 336 (55.7\%) females (Figure 1).

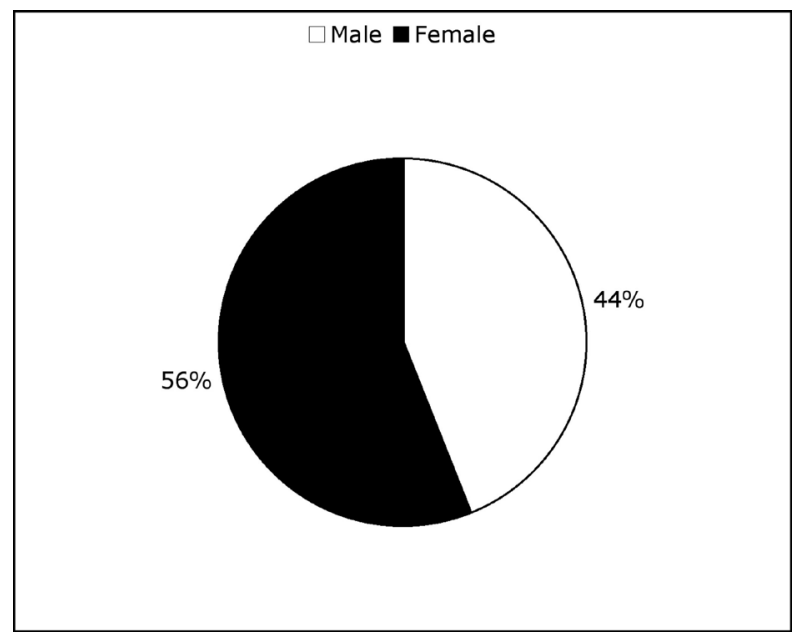

Figure1: Gender distribution of patients with PID

All patients were offered conservative management which included analgesics, bed rest. Five per cent of the patients were put on bilateral traction for two weeks while $4 \%$ of the patients had corsets. Two hundred and thirteen patients (35\%) were given surgical management. These included 118 females (55.3\%) and 95 males (44.7\%); (Table 2). Surgical options included microdiscectomy, laminectomy, fenestration and decompression (method unspecified), (Figure 2).

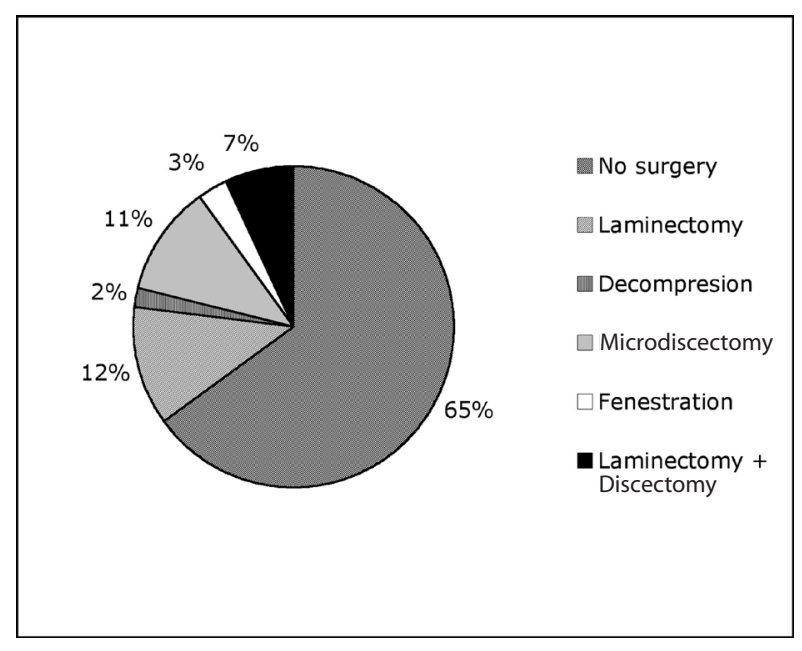

Figure 2: Management of PID at $\mathrm{KNH}$

The commonest surgical method was laminectomy (Figure 2), $p=0.775$. Microdiscectomy, though not used initially became the choice surgical operation method by the end of the study period (Table 1). The site of disk herniation didn't influence the type of surgery used ( $p=0.07$ ), (Table 3). Most of the patients improved after management (Table 4). Complications after management included persistent pain, reoperation, pulmonary embolism and incontinence (Table 5). Recurrence of the herniation occurred in seven cases (Table 5). In three of the cases there was reherniation at the same level while in the rest it was at another level. The outcome of management was dependent on the level of herniation, disk status and number of disk herniations. Patients with pulmonary embolism and incontinence as surgical complications had multiple disc prolapses. There was no relationship between the complication and the surgical method used.

Table 1

Year first seen vs surgery type

\begin{tabular}{lcccccc}
\hline Year & Microdiscectomy & Laminectomy & Fenestration & Decompression & Laminectomy + Discectomy & Total \\
\hline 1997 & 0 & 4 & 0 & 0 & 0 & 2 \\
1998 & 0 & 4 & 1 & 0 & 5 & 7 \\
1999 & 1 & 5 & 3 & 0 & 5 & 14 \\
2000 & 4 & 16 & 2 & 3 & 8 & 30 \\
2001 & 4 & 11 & 1 & 2 & 4 & 26 \\
2002 & 4 & 7 & 1 & 2 & 8 & 18 \\
2003 & 6 & 10 & 2 & 1 & 2 & 27 \\
2004 & 6 & 4 & 0 & 1 & 1 & 13 \\
2005 & 6 & 2 & 3 & 0 & 4 & 12 \\
2006 & 14 & 4 & 4 & 2 & 4 & 28 \\
2007 & 20 & 5 & 1 & 2 & 43 & 31 \\
\hline Total & 65 & 72 & 18 & 13 & & 213 \\
\hline
\end{tabular}


Table 2

Gender versus surgery type

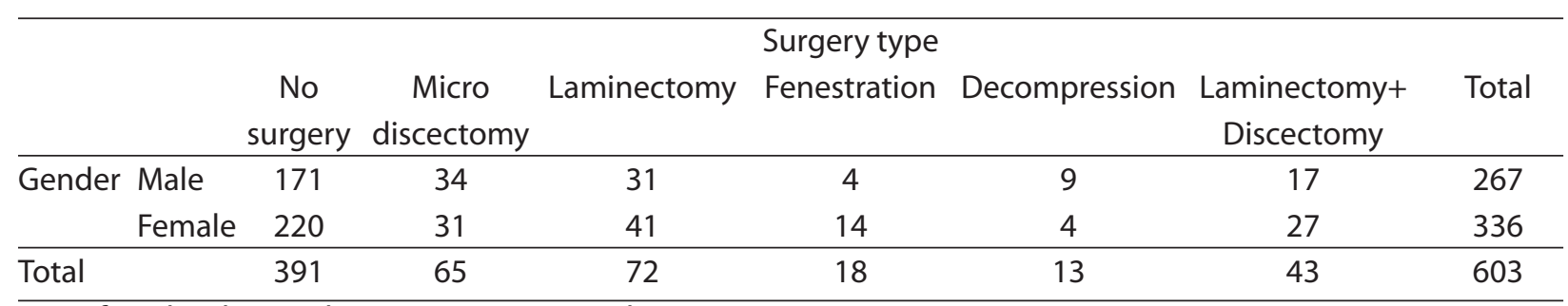

More females than males were given surgical care

Table 3

Comparing the site of herniation to the surgery type

\begin{tabular}{|c|c|c|c|c|c|c|c|c|}
\hline & \multicolumn{8}{|c|}{ Surgery type } \\
\hline & & $\begin{array}{c}\text { No } \\
\text { surgery }\end{array}$ & $\begin{array}{c}\text { Micro } \\
\text { discectomy }\end{array}$ & Laminectomy & Fenestration & Decompression & $\begin{array}{l}\text { Laminectomy+ } \\
\text { Discectomy }\end{array}$ & Total \\
\hline \multirow[t]{12}{*}{ Site } & Not & & & & & & & \\
\hline & indicated & 235 & 3 & 3 & 0 & 2 & 1 & 244 \\
\hline & $\llcorner 4,5$ & 77 & 26 & 33 & 7 & 2 & 11 & 156 \\
\hline & $\mathrm{L} 1,2$ & 3 & 0 & 0 & 0 & 0 & 0 & 3 \\
\hline & $\mathrm{L} 3,4$ & 6 & 1 & 3 & 1 & 0 & 2 & 13 \\
\hline & $\mathrm{L} 5, \mathrm{~S} 1$ & 32 & 24 & 17 & 5 & 0 & 15 & 93 \\
\hline & Cervical & & & & & & & \\
\hline & disk & 1 & 2 & 0 & 0 & 5 & 1 & 9 \\
\hline & 2 disks & 27 & 7 & 14 & 5 & 4 & 10 & 67 \\
\hline & $>2$ disks & 5 & 2 & 1 & 0 & 0 & 2 & 10 \\
\hline & $\mathrm{L} 1, \mathrm{~L} 2$ & 3 & 0 & 1 & 0 & 0 & 1 & 5 \\
\hline & Total & 390 & 65 & 72 & 18 & 13 & 43 & 601 \\
\hline
\end{tabular}

Table 4

Prognosis

\begin{tabular}{lcc}
\hline Outcome & Frequency & $(\%)$ \\
\hline No change & 17 & 2.8 \\
Improved & 576 & 95.5 \\
Deteriorated & 1 & 0.2 \\
Recurrent disk prolapse & 9 & 1.5 \\
\hline Total & 603 & 100 \\
\hline
\end{tabular}

Table 5

Complication of surgery

\begin{tabular}{lcc}
\hline Complications & Frequency & $(\%)$ \\
\hline No complications & 196 & 92.0 \\
Persistence of pain & 4 & 1.9 \\
Reoperation & 7 & 1.2 \\
Clinical deterioration & 3 & 2.3 \\
Pulmonary embolism & 2 & 0.9 \\
Incontinence & 1 & 0.4 \\
\hline Total & 213 & 100 \\
\hline
\end{tabular}




\section{DISCUSSION}

Conservative and surgical methods of managing PID have been described (4). While all the patients received some form of conservative care, less than a half of our patients received surgical care. The choice of whether to surgically or conservatively manage a patient is both surgeon and patient dependent. Some authors however argue that patients will still improve whether they are managed surgically or not (5). Excision of a herniated disc for relief of sciatica provides rapid relief of sciatica and low-back pain (6). In the younger patients it is important to aim toward an early return to school or duty via surgical treatment (7). Marrying both conservative and surgical care in PID may be more beneficial to an individual patient with different attributes.

Most (92\%) of our patients didn't have any complications following surgery. Success rates for lumbar disc surgery ranges from $46-96 \%$ (8). The outcome of the lumbar discectomy depends more on the patient selection than on the surgical technique (1). Although there was no significant difference between the outcomes by the different surgical methods, when a standard discectomy is used, the overall success rate is $85 \%$ and $95 \%$ of the patients with successful surgery return to work (3). The best result is achieved if the patient was operated on before two months' duration of disabling sciatica (2). Therefore the long-term outcome of standard discectomy is favorable (9). Interlaminar lumbar discectomy by fenestration method without extensive laminectomy is also effective and reliable surgical technique for treating properly selected patients with herniated lumbar disc at L4-L5 and L5-S1 levels (1).

The outcome of management is more dependent on the choice of the type of patient rather than the choice of method of management. Some authors have suggested that microdiscectomy in patients with disc herniations at the L5-S1 level have significantly better outcomes than those at the L4-L5 level (10). In contradistinction other authors have argued that the smallest treatment effects are seen at L5-S1, intermediate effects at L4-L5, and the largest effects at L2-L3 and L3L4 (7). Patients with sequestered or extruded lumbar disc herniations have significantly better outcomes than those contained herniations. Patients with contained disc herniations, a predominance of back pain, on restricted duty and smoking should however be counseled before surgery of the potential for less satisfaction, poorer outcomes scores, and decreased return to duty rates $(10,12)$.

Seven patients in our study had reoperation following reherniation. In a review for reasons of 100 disc prolapses reoperations it was found in $62 \%$ a recurrence of disc prolapse at the same level, in $24 \%$ a recurrence at a different level, whereas in $14 \%$ it was found that the nerve route was closely connected (13). Although we didn't document the time taken before the reherniations, the rate of early reherniation after lumbar discectomy is documented to be low (1\%) (14). Reherniation rates within two years after sequestrectomy and microdiscectomy are comparable. However, outcome after microdiscectomy seems to worsen over time, whereas it remains stable after sequestrectomy (15). It is important to consider the possibility of iatrogenic instability during surgery on the lumbar spine for the treatment of reherniation (14). Patients who undergo reoperation because of early recurrent lumbar disc herniation can have clinical outcomes comparable with those of patients undergoing an uncomplicated subtotal lumbar discectomy. Surgical treatment of recurrent sciatica after disc excision is rewarding in most cases of recurrent herniation but not in fibrosis and scarring (16).

In conclusion, the management of PID at Kenyatta National hospital is largely successful with few cases of complications. The type of patient rather than the method of surgery determines outcome of surgery. In selected patients both conservative and surgical care are used in tandem. Microdiscectomy is an increasingly popular surgical procedure at the $\mathrm{KNH}$.

\section{REFERENCES}

1. Manohara Babu, KV. Surgical management of lumbar disc prolapse by fenestration technique. J. Orthopaedics. 2006; 3(4) e6.

2. Deyo, R. A. Non-operative treatment of low back disorders: differentiating useful from useless therapy. In: Frymoyer J.W., editor. The adult spine: principles and practice. New York: Raven Press. 1991; 1559-1560.

3. Kendall, D. The etiology, diagnosis, and treatment of prolapsed intervertebral disk, with a review of 300 cases of sciatica. Q. J. Med. 1947; 16: 157-179.

4. Zeng Yan-Fen. Clinical observation on treatment of 67 cases with lumbar. Intervertebral disc herniation with abdomen acupuncture. J. Acupunct. Tuina. Sci. 2008; 6: 42-45. DOI: 10.1007/s11726-008-0042-z. 
5. Weinstein, T. N., Tosteson, T. D., Lurie, J. D., et al. Surgical vs nonoperative treatment for lumbar disk herniation. The Spine Patient Outcomes Research Trial (SPORT): A randomized trial. JAMA. 2006; 296: 2441-2450.

6. Toyone, T., Tanaka, T., Kato, D. and Kaneyama, R. Lowback pain following surgery for lumbar disc herniation. $A$ prospective study. J. Bone Joint Surg (Am). 2004; 5: 86-A(5): 893-896.

7. Ishihara, H., Matsui, H., Hirano, N. and Tsuji, H. Lumbar intervertebral disc herniation in children less than 16 years of age. Long-term follow-up study of surgically managed cases. Spine. 1997; 22 (17): 2044-2049.

8. Spengler, D. M. Results with limited disc excision. Spine. 1982; 7: 604- 607.

9. Yorimitsu, E., Chiba, K., Toyama, Y. and Hirabayashi, K. Long-term outcomes of standard discectomy for lumbar disc herniation: a follow-up study of more than 10 years. Spine. 2001; 26 (6): 652-657.

10. Dewing, C. B., Provencher, M. T., Riffenburgh, R. H., Kerr, S. and Manos, R. E. The outcomes of lumbar microdiscectomy in a young, active population: correlation by herniation type and level. Spine. 2008; 33(1): 33-38.

11. Lurie, J. D., Faucett, S. C., Hanscom, B., et al. Lumbar discectomy outcomes vary by herniation level in the Spine Patient Outcomes Research Trial. J. Bone Joint Surg (Am). 2008; 90(9):1811-1819.
12. Chin, K. R., Tomlinson, D. T., Auerbach, J. D., Shatsky, J. B. and Deirmengian, C. A. Success of lumbar microdiscectomy in patients with modic changes and low-back pain: a prospective pilot study. J. Spinal Disord. Tech. 2008; 21(2):139-144.

13. Reith, C., Lausberg, G. and Wildförster, U. Etiology of the recurrence of lumbar intervertebral disk displacement. Neurochirurgia (Stuttg). 1989; 32(1):5-9.

14. Wera, G. D., Marcus, R. E., Ghanayem, A. J. and Bohlman $\mathrm{H}$. $\mathrm{H}$. Failure within one year following subtotal lumbar discectomy. J Bone Joint Surg (Am). 2008; 90 (1): 10-15.

15. Barth, M., Diepers, M., Weiss, C. and Thomé, C. Twoyear outcome after lumbar microdiscectomy versus microscopic sequestrectomy: part 2: radiographic evaluation and correlation with clinical outcome. Spine. 2008; 33(3): 273-279.

16. Jönsson, B. and strömqvist, B. Clinical characteristics of recurrent sciatica after lumbar discectomy. Spine. 1996; 21 (4): 500-505. 